\title{
Analysis of the Learning Mode of an Elaborate Resource Sharing Course
}

\author{
http://dx.doi.org/10.3991/ijet.v11i09.6110 \\ Ken Cai ${ }^{1}$, Yingying Jin ${ }^{2}$, Hongwei Yue ${ }^{2}$ and Haoran Huang ${ }^{1}$ \\ ${ }^{1}$ Zhongkai University of Agriculture and Engineering, Guangzhou, China \\ ${ }^{2}$ Wuyi University, Jiangmen, China
}

\begin{abstract}
Educational informatization and networking have become inevitable because of the major changes in the course content system and teaching modes. Examining the status of the development of an elaborate resource sharing course (ERSC) and analyzing the sharing and application of educational resources are important. Through a comparative analysis of foreign open classes and domestic resource sharing courses, this paper puts forward recommendations for the sharing of resources and communication between teachers and students in the development of an ERSC. Positive interactions between teachers and students are promoted in network-based teaching using the WeChat public platform to build a virtual learning environment. Then, this paper analyzes the effect of intellectual property right protection of network teaching on open educational resources and proposes countermeasures. Results show that the WeChat teaching technology and the cited standards for the public educational resources can improve learning efficiency. These findings can also serve as reference for promoting the sustainable development of ERSC.
\end{abstract}

Index Terms-Sharing course, WeChat learning platform, Educational resources, Learning mode

\section{INTRODUCTION}

Open sharing of educational resources in the field of higher education is a controversial issue that raises concern among education researchers and users. The practice, which combines the open sharing, public interest, and knowledge characteristics of online educational resources as well as the multimedia information technology-based model, has gradually become part of the strategic reform measures of many higher-education institutions.

To enhance the sustainable development of teaching quality and quality education resources in colleges and universities, and to promote equality in higher education, the National Program of Web-Delivery for Elaborate Courses (NPWDEC) was included in the National Outline for Medium and Long-term Education Reform and Development (2010-2020) [1]. The outline is a major reform of the education business in China. It aims to develop demonstration lessons characterized by five "first-class" aspects, namely, first-class teachers, first-class teaching content, first-class teaching methods, first-class teaching materials, and first-class management, to facilitate the spread and development of ideas and high-quality teaching resources in higher education $[2,3,4]$.

As an important part of NPWDEC, the development of an elaborate resource sharing course (ERSC) is designed to promote the transformation of education ideas and to serve self-learning students in school and learners from society to popularize and share quality curriculum resources. By focusing on widely used and various basic and specialized courses using network openness and sharing, ERSC aims to lead the reform in teaching methods and course content, promote and realize high-quality teaching resource sharing, and improve the quality of personnel training to serve the learning society.

Currently, the problem in developing ERSCs in college and universities remains to be the use of information technology to expand the extent of resource sharing in ERSC to maximize its major role in the learning society. Present concerns include studying the construction mode of ERSC under the information environment, enhancing ERSCs' demonstrative level and influence, expanding and meeting the needs of learners, and creating new ERSCs.

\section{STATE Of The ART}

Today's wave of information technology injects a new educational philosophy into the Reform of Higher Education. Openness, interaction, sharing, collaboration, and autonomy of the information environment provide new opportunities for the widespread development of ERSCs in colleges and universities. ERSCs make optimal use of modern information technology tools to improve teaching methods and apply an advanced educational philosophy as a guide to break the traditional school-based course development mode, thus developing fully open ERSCs oriented toward teachers, students, and learners in society to develop students' awareness of self-exploration and fully stimulate learners' interest and capability [5,6,7].

As early as 2001, after the Massachusetts Institution of Technology (MIT) pioneered the Open Course Ware, a number of universities and educational institutions, including Yale University and Stanford University, also launched open educational resource programs called Massive Open Online Courses (MOOC), which have attracted increasing attention since $2012[8,9,10,11]$. NPWDEC, which was launched by the Ministry of Education in 2003, was inspired by the open educational resources movement [12].

Amid the growing concern about the quality of higher education around the world, the Ministry of Education responded to the trend of the times by launching the requirements of "cultural heritage innovation to comprehensively improve the quality of education." For the 12th Five-year Plan period, the "undergraduate teaching project" plans to build 5,000 national and 10,000 provincialand school-level ERSCs, for which 1,027 courses have been successfully created. Oriented toward college teachers, students, and learners in society, ERSCs aim at teaching a variety of network sharing courses, including basic 


\section{SHORT PAPER}

\section{ANALYSIS OF the LEARNING MODE OF AN ElabORATE RESOURCE SHARING COURSE}

and specialized courses. The development of ERSC is mainly divided into two areas: 1) upgrading the former merit-based national elaborate courses into national ERSCs based on teaching reform and personnel training needs, and 2) developing new ERSCs that adopt two construction modes of selecting for access and tendering for development.

\section{Comparative Analysis Of The Development OF COURSE RESOURCE}

For an in-depth comparison of the similarities and differences between the two courses, this paper takes "NetEase open course" (http://open.163.com/)[13] and iCourse (http://www.icourses.cn/) as objects of the study to identify the existing deficiencies in China's ERSC development. As a representative of open class on China's commercial websites, the NetEase open course uses exemplary curriculum, learning, and communication models. In the NetEase open course, learners can watch free highquality online videos of courses from MIT and other prestigious international schools. Its contents cover humanities, social studies, arts, finance, and other fields. Soon after its emergence, the NetEase open course earned a good reputation and became popular with the public. Conversely, iCourse is the resource sharing platform of the higher education curriculum that supports and develops the "undergraduate teaching project," which was co-launched and co-implemented by the Ministry of Education and Ministry of Finance during the 12th Five-year Plan period. To a certain extent, the ERSCs and personalized teaching resources and services provided to a large number of learners through the iCourse platform have promoted the wide dissemination and sharing of high-quality curriculum resources.

\section{A. Communication and Interaction}

ERSCs are not only oriented toward college students but also toward the majority of learners in society. Therefore, communication and interaction with these online users should be taken into consideration. By observing the NetEase open courses and iCourse, this study presents two prerequisites for interaction: to allow users, teachers, or other experts and provide them with service modules to communicate on the platform and to enable instructors to participate in the communication and interaction.

The comparative analysis of communication and interaction in the NetEase open and iCourse resource sharing courses clearly indicates that learners from both platforms have minimal communication or cannot communicate with their instructors, whereas learners from the traditional classroom can exchange their learning experiences with one other. This result is due to the different permissions allowed by the platforms to learners, thus resulting in different permissions for communication between learners and videos, and among the learners themselves. Moreover, communication and interaction in the NetEase open courses are easier and more in-depth than those in iCourse.

\section{B. Construction and Sharing}

Network sharing of ERSCs is intended to facilitate access to courses in compliance with the Internet age, and it is conductive to the promotion of courses. An analysis and summary of the conditions of learning resources provided by the NetEase open course are illustrated in Figure 1. The NetEase open course provides learners with four aspects for their study: briefing on the natural conditions, content introduction, auxiliary resource download, and platform for communication and interaction. Curricular auxiliary resources are available for learners to download videos and courseware. Learners can communicate with each other through note taking and discussion.

As shown in Figure 2, the classification of resource development from the iCourse resource sharing courses is similar to that provided by the NetEase open courses although each category has differing contents. Although presentations, exercises, and courseware, among others, are made available in the "curricular auxiliary resources" module, they do not support learners' downloads, thus affecting learners' self-learning to a certain extent. In the "communication and interaction" module, iCourse is equipped with the functions of study notes and Q\&A discussion.

After-school or homework exercises not only can facilitate the consolidation of knowledge but also give learners a sense of accomplishment after learning. Only with appropriate feedback after homework submission can learners recognize the problem areas that they need to work on. Thus, a comparative analysis of homework submission conditions and system feedback conditions in the NetEase open course and iCourse platforms is conducted as shown in Figure 3. Figure 3 indicates that homework and feedback resources are sufficient on the NetEase open course platform, and that the proportion of feedback is even $56 \%$ higher than that on the iCourse platform. The feedback result indicates that the NetEase open course platform enables greater involvement than iCourse in the overall learning outcomes of learners, and thus the enthusiasm of learners is easily mobilized. By contrast, sharing courses still require much improvement. Moreover, the key to maintaining efficient and durable construction is to begin from the adequacy of resources.

From the above comparative analysis, the comprehensive quality of the course is determined by the service level of learning support of the network open class. The main problems are sharing and interactive communication during the courses. How to improve on these two problems is discussed in the following section.

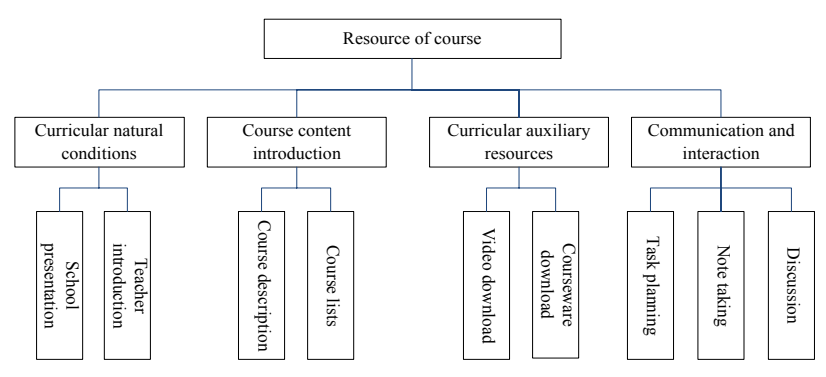

Figure 1. Conditions of resource construction provided by the NetEase open course

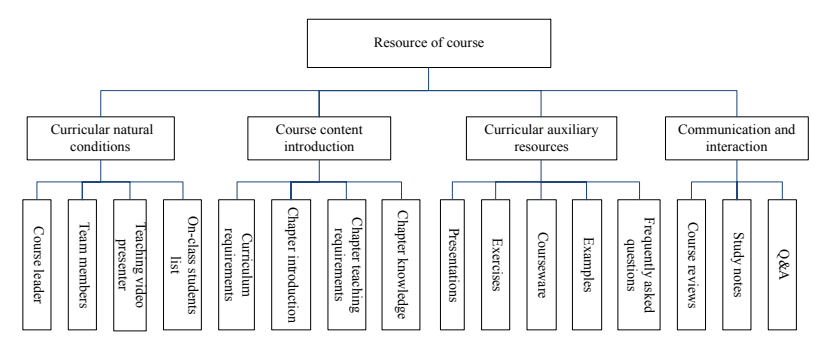

Figure 2. Conditions of resource construction provided by iCourse 


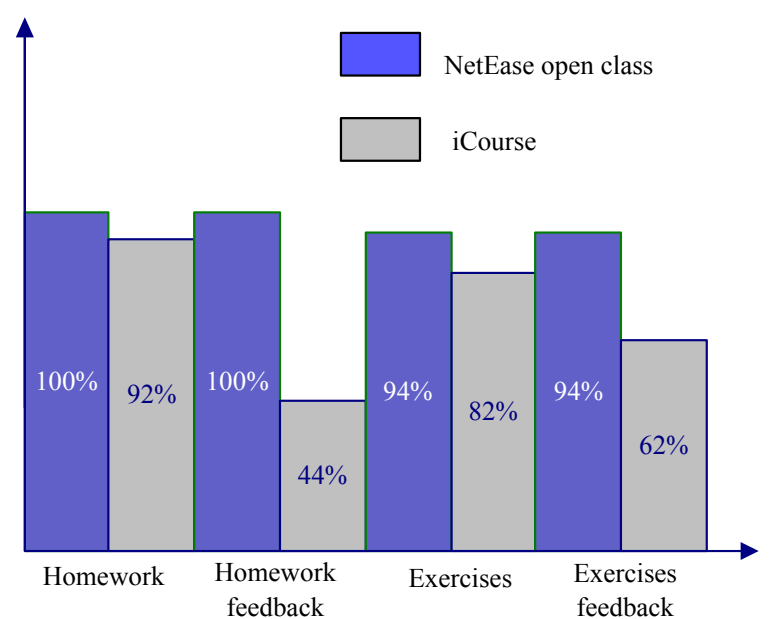

Figure 3. Comparison of feedback

\section{LEARning Mode Design Of THE Wechat LEARNING PLATFORM}

Adjusting the existing teaching support environment is necessary for a mobile network in colleges and universities under the traditional network transitioning to the mobile network. Tencent's WeChat is a new mobile platform application that has more than 350 million registered users. It supports voice messaging, video, images, and text, thus making it suitable for most smartphones. Based on these features, the WeChat public platform is proposed to build the teaching support environment to comply with the technical development and meet the application orientation of college students. In the WeChat teaching platform, the teacher establishes the teaching platform and provides the following modules: learning material module, teaching activity organization module, homework module, and answer and interaction module (see Figure 4). Using the platform, students can check for learning updates, view resources and task lists at any time, undergo training and tests, and communicate timely with others.

By analyzing the function of the WeChat public platform, a framework for the WeChat learning platform is developed. As shown in Figure 5, the learning activity design mode based on the WeChat learning platform is proposed according to the results of a previous investigation. This platform can generate a desirable informal learning experience using technological advantages. Furthermore, the ideas and methods of the teaching design are required to enhance the learning activity design.

Through WeChat, learners not only can have one-toone conversations but also initiate group discussions. They can also send and share links in the friend circle, which enables produce synchronous communication and asynchronous messages. Teaching organizers or educators can use the group chat, group function, or friend circle to promote knowledge points, problems, and related resources. Moreover, they can establish a special WeChat public platform related to a certain subject. Educators can use these WeChat functions to organize appropriate teaching activities. Participants can then share and interact through the voice information, video information, graphic information, and links as shown in Figure 6.

Regarding interaction, the learners themselves can also become essential resources for other learners. Different

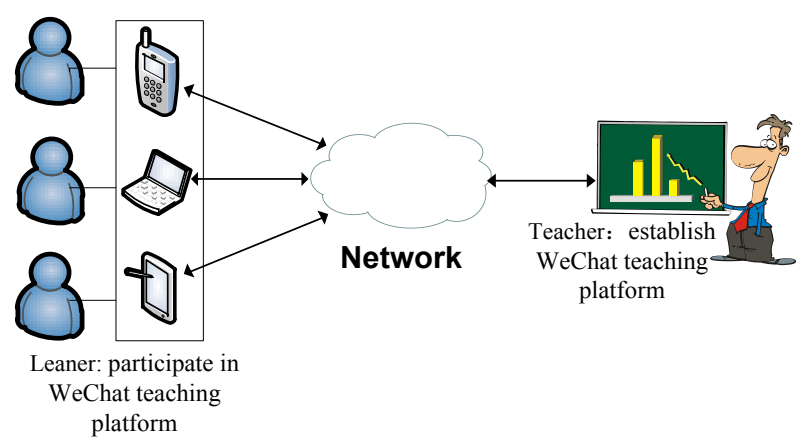

Figure 4. Network teaching based on the WeChat public platform

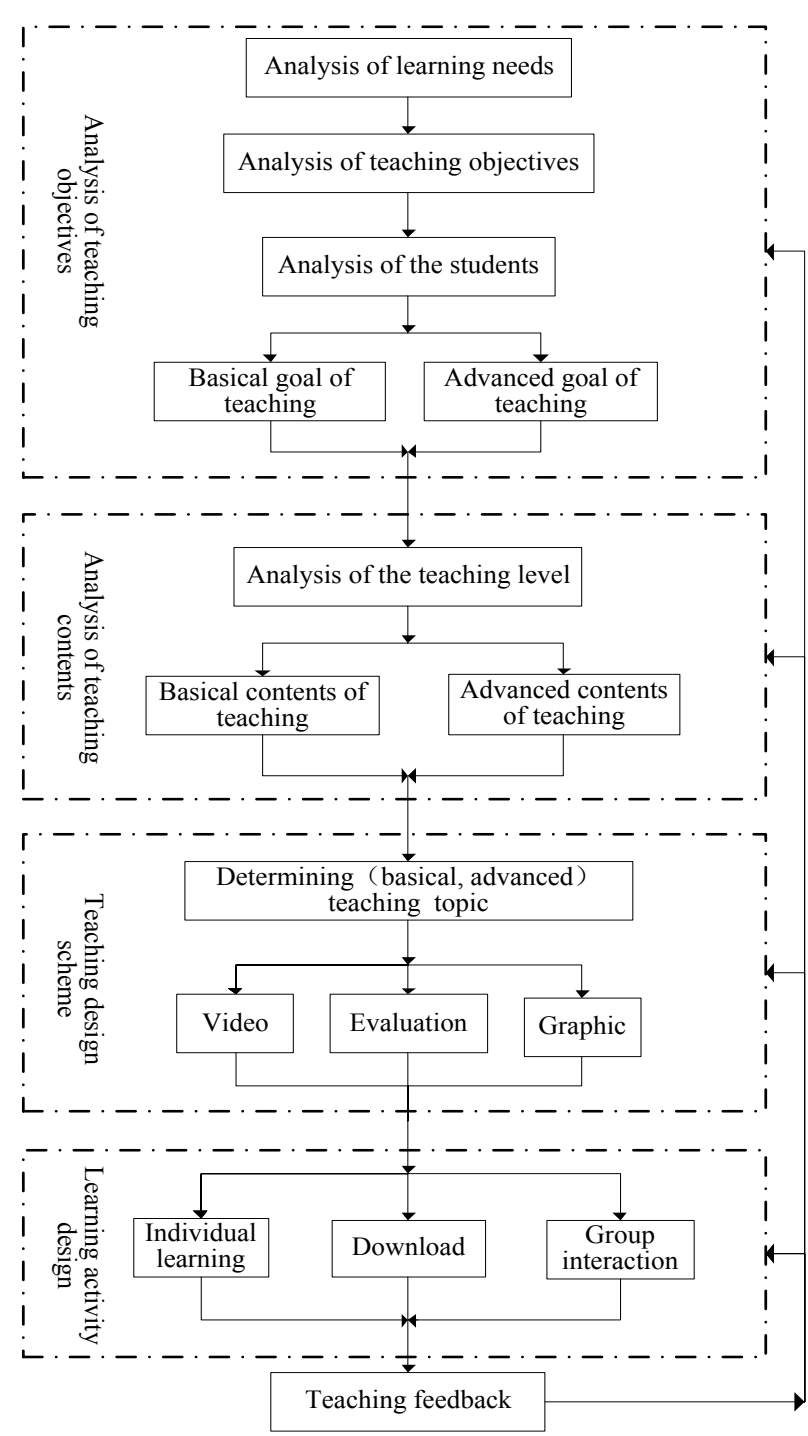

Figure 5. Learning activity design mode supported by the WeChat learning platform

learners can have different viewpoints, which can be merged to produce different sparks of understanding. The sparks provide different perspectives for learners to solve problems, and they are valuable resources for learners and conducive to extending their knowledge and cultivating their creativity. Through the "voice," "multi group chat," and "friend circle" functions of WeChat, learners can transcend limitations in time, space, and character. In the process of chatting, learners can enhance their mindsets and generate new ideas. 


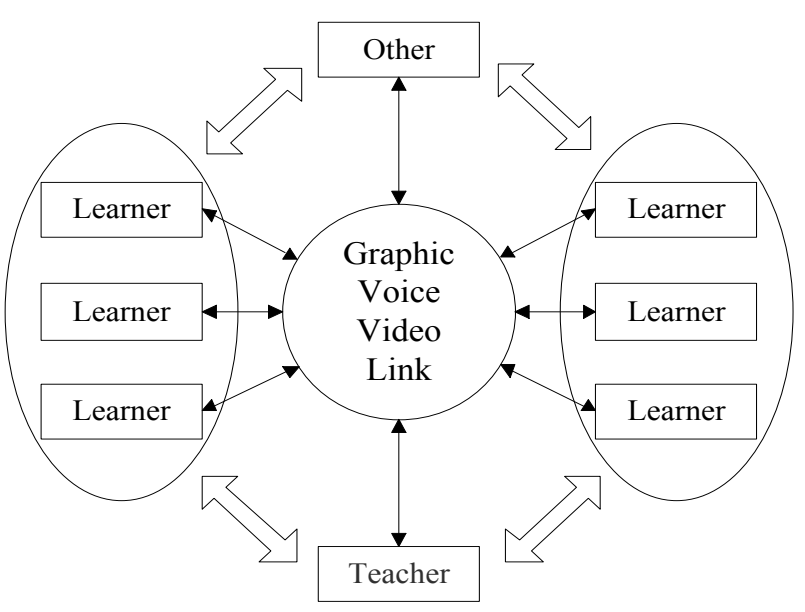

Figure 6. Interactive module based on the WeChat public platform

\section{COUntermeasures And Suggestions}

As educational resources, ERSCs have their own characteristics that set them apart from traditional educational resources. Network sharing notably guarantees the uniqueness of their marketing and use. Currently, the following questions exist in the development of ERSCs in college and universities.

\section{A. Improvement of Communication in Network Teaching}

At present, iCourse and NetEase open courses provide platforms for communication among learners, but communication between teachers and students in the classroom recording is rare and not interactive. When communicating with online users, instructors barely address their questions and do not provide the opportunity for indepth exchanges on a specific issue. These conditions clearly go against learners' desire for knowledge. ERSCs have launched a teaching activity function, but it has not been successfully implemented or does not have the function of assigning learners certain tasks. Thus, learning becomes a one-way output, and this simple input is not conducive to exercising learners' ways of thinking. Teachers and learners cannot be completely separated. However, online learning communication and interaction cannot truly realize a live classroom interaction unless it implements changes that require the use of an appropriate network technology to enable both teachers and learners to be organically associated with the learning platform.

A great demand exists for learning through the rapid development of Internet technology and the wide application of social software support. Specifically, the mobile development of the Internet, which enables users to learn any time and at any place, promotes the study of life and socialization, and provides favorable conditions for lifelong learning. As a typical representative of domestic mobile Internet applications, WeChat is not only a platform for users to have a wealth of interactive communication but also that for effectively supporting the implementation of learning activities.

\section{B. Enhancement of Resource Sharing}

Teachers, colleges, and universities regard the development of ERSCs as a means to achieve their ultimate goal of passing the national and provincial assessments. For them, the development of sharing resource is simply to improve the reputation of the school or complete the school teaching evaluation and other performance targets. Some schools are also concerned about their achievements being stolen by others after resource sharing, thus undermining the competitiveness of their "name-brand" courses. Therefore, they refuse to share with other universities, an action indicating that shared consciousness is relatively weak in the process of developing a shared curriculum. Moreover, course acquisition presents intellectual property issues, and the intellectual property protection of ERSCs has been discussed in only a few documents in China. The intellectual property of network teaching resources remains unclear, and the interests of teachers or schools are not guaranteed either, thus leading to low enthusiasm about curriculum development. Consequently, an obstacle to course acquisition is created, and it is a serious violation of the original intention to promote fairness in quality education resource and sharing through ERSCs. Teaching resources, as the fruit of mental work, deserve intellectual property protection. The establishment of academic standards (similar to those of the references cited) for the achievement of online public educational resources sharing can effectively protect the interests of all parties involved.

\section{CONCLUSION}

To enhance the demonstrative level and influence of ERSCs and to expand and meet the needs of learners in the information environment, this paper analyzed the construction mode and application status of ERSCs. The following conclusions were obtained:

(1) Through the WeChat learning platform, learners who cannot be bound by time and place can develop informal learning habits to achieve systematic learning in a fragmented time.

(2) Through the "voice," "multi group chat," and "friend circle" functions of WeChat, the new mobile education platform not only has a profound effect on the life and learning of students but also provides a new learning interaction environment for improving teaching and learning.

(3) Uniformity and conflict are two issues coming between information resource sharing and intellectual property rights. Information resource sharing may help to promote public access to information resource while simultaneously infringing on intellectual property rights. In terms of ERSC, the lack of protection of the interest of teachers or schools inhibits resource sharing. Establishing academic standards for public educational resources similar to those indicated in the references cited is an effective way to improve the above problems.

With advanced educational philosophy as a guide, ERSCs are designed to break the traditional school-based course construction, develop students' awareness of selfexploration with the scientific use of mixed teaching methods, and stimulate learners' interests and abilities by maximizing modern information technology tools. Promoting the development of ERSC improves the quality of personnel training to service the learning society and enhances education teaching achievement. Future research should target the establishment of innovation mechanisms to strike a balance between the protection of intellectual property rights and public access to information resource. 


\section{SHORT PAPER}

\section{ANALYSIS OF THE LEARNING MODE OF AN ElabORATE RESOURCE SHARING COURSE}

\section{REFERENCES}

[1] M. Gu, "Study and Interpretation on State Planning Outline for Medium and Long-term Education Reform and Development (2010-2020) ," Journal of Higher Education, vol. 31, pp. 1-6, July 2010.

[2] R. Feng, "Inspiration of world open courses on China's state benchmark courses," China Educational Technology, vol. 301, pp. 17-21, February 2012.

[3] Q. L. Lu, H. Sun, Y. Tian, Y. Xie, and S. P. Wei, "Investigation of China's state benchmark courses,"Distance Education in China, vol. 31, pp. 78-87, April 2010.

[4] J. R. Zhang, "Education construction and sharing: a forum summary," China Educational Technology, vol.3, pp. 30-36, March 2011 .

[5] L. Liang, Q. Cao, and B. Zhang, "Research on a micro-lecture design model through comparative case study," Open Education Research, vol. 19, pp. 65-73, January 2013.

[6] J. L. Zhang, W. Ying, and B. H. Zhang, "Introducing a new teaching model: flipped classroom," Journal of Distance Education, vol. 30 , pp. 46-51, August 2012.

[7] C. F. Herreid, and N. A. Schiller, "Case studies and the flipped classroom,"Journal of College Science Teaching, vol.42, pp. $62-$ 66, June 2013.

[8] K. M. Alraimi, H. Zo, and A. P. Ciganek, "Understanding the MOOCs continuance: The role of openness and reputation," Computers \& Education, vol. 80, pp. 28-38, January 2015. http://dx.doi.org/10.1016/j.compedu.2014.08.006

[9] B.Stewart,"Massiveness+openness=new literacies of participation?,"Journal of Online Learning and Teaching, vol.9, pp. 228238, March 2013.

[10] D. T. Seaton, Y. Bergner, I. Chuang, P. Mitros, and D. E. Pritchard,"Who does what in a massive open online course," International Jjournal of Human-computer Studies, vol.68, pp. 223241, September 2013.

[11] J. Reich, "Rebooting MOOC research," Science, vol.347, pp. 34 35, January 2015. http://dx.doi.org/10.1126/science.1261627

[12] Z. Jiang,"Chinese quality open video courses-analysis on problems and promote strategies," Asian Social Science, vol.11, pp. 78-83, November 2015. http://dx.doi.org/10.5539/ass.v11n25p78
[13] R. Saadatdoost, A. T. H. Sim, H. Jafarkarimi, and J. M. Hee, "Understanding the setting of a MOOC: a journey into coursera," International Journal of Information and Communication Technology Education, vol.12 , pp. 77-98, January 2016. http://dx.doi.org/10.4018/IJICTE.2016010107

\section{AUTHORS}

Ken Cai is with the School of Information Science and Technology, Zhongkai University of Agriculture and Engineering, Guangzhou, 510225, China (e-mail: icken@126.com).

Yingying Jin (Corresponding author) is a lecturer of School of Mathematics and Computational Science, Wuyi University, Jiangmen, China. Her research interests include General topology and Multimedia courseware (email: crescentlake@126.com).

Hongwei Yue is a lecturer of School of Information Engineering, Wuyi University, Jiangmen, China. His research interests include image processing, network and information security (e-mail: yuehognwei@163.com).

Haoran Huang is with the School of Information Science and Technology, Zhongkai University of Agriculture and Engineering, Guangzhou, China (e-mail: 93643764@qq.com).

This work was supported by the "Twelfth Five-Year" Plan Youth Program of National Education Information Technology Research (No.146242186), the Guangdong Provincial Program for Elaborate Resource Sharing Course, the Cultivation Program of Educational and Teaching Achievement Prize in Guangdong Province, the Features Innovative Program in Colleges and Universities of Guangdong (No.2015KTSCX069), the Pearl River S\&T Nova Program of Guangzhou (No.201506010035), the Project of Outstanding Young Teachers' Training in Colleges and Universities of Guangdong (No. YQ2015091), the Undergraduate Teaching Quality and Teaching Reform Project of Wuyi University(No. JX2016025).

Submitted, 09 March 2015. Published as resubmitted by the authors on 09 April 2015. 